\title{
Palatability and Sensory Perception of Infant Formulas for the Treatment of Cow's Milk Allergy According to Brazilian Mothers
}

\author{
Matias Epifanio ${ }^{1 *}$, Camila Leonel Mendes de $\mathrm{Abreu}^{2}{ }^{2}$ Karina Barros $^{3}$, Juliana Oviedo ${ }^{4}$, Andre Covic ${ }^{5}$ \\ and Rita de Cássia SC Ormenese ${ }^{6}$ \\ ${ }^{1}$ Professor in the Pontifical Catholic University of Rio Grande do Sul. \\ ${ }^{2}$ Danone Early Life Nutrition, Brazil \\ ${ }^{3}$ Danone Early Life Nutrition, Brazil \\ ${ }^{4}$ Danone Early Life Nutrition, Brazil \\ ${ }^{5}$ Universidade Estadual de Campinas, Brazil
}

${ }^{6}$ Instituto de Tecnologia de Alimentos (ITAL), Brazil

*Corresponding author: Matias Epifanio, Professor in the Pontifical Catholic University of Rio Grande do Sul,AV Luiz Manoel Gonzaga 630 casa 3 No, Brazil

\begin{tabular}{l} 
ARTICLE INFO \\
\hline Received: 业 January 20, 2020 \\
Published: 㓞 January 29, 2020 \\
\hline
\end{tabular}

Citation: Matias Epifanio, Camila Leonel Mendes de Abreu, Karina Barros, Juliana Oviedo, Andre Covic, Rita de Cássia SC Ormenese. Palatability and Sensory Perception of Infant Formulas for the Treatment of Cow's Milk Allergy According to Brazilian Mothers. Biomed J Sci \& Tech Res 25(1)-2020. BJSTR. MS.ID.00416.

Keywords: Cow's Milk Allergy; Cow's Milk Hydrolyzed Formulas; Amino Acid-Based Formula; Palatability

\begin{abstract}
Introduction: Cow's milk allergy (CMA) is the most prevalent allergic manifestation in the world pediatric population. The treatment is based on the exclusion of the milk proteins from the diet of the nursing mother or, in the case of new-born babies using infant formulas, the use of infant formulas with extensively hydrolyzed proteins (eHF) or free amino acids (AAF). However, the taste of the eHF may represent an obstacle to the treatment, which is basically dietary. The objective of this study was to measure the sensorial perceptions of different infant formulas for the treatment of cow's milk allergy, according to Brazilian mothers of infants with this clinical condition.
\end{abstract}

Methodology: Randomized blind study of 90 women, mothers of children with CMA. Five different types of formulas aimed at the treatment of CMA were evaluated, without identification of type, brand or manufacturer, in relation to acceptability and preference.

Result: Evaluation of the appearance, smell, flavor and aftertaste of the powders and prepared products showed similar orders of preference, with only slight differences in discrimination. All results showed that whey based eHF were chosen as better palatable compared to eHF based on rice and casein and AAF. Overall and aftertaste liking of the rice based eHF was better than for casein based eHF and for AAF; smell and flavor liking was better for rice based eHF than for casein based eHF.

Conclusion: Whey hydrolyzates were more palatable than other eHF and amino acid formula, which is a potential advantage in the maintenance of an adequate intake for children on a CMA diet.

\section{Introduction}

Cow's milk allergy (CMA) is a consequence of an abnormal immune response to cow's milk proteins. Its incidence in infants from industrialized western countries is estimated to be around $2-3 \%$ [1]. Among food allergies, CMA is the most prevalent allergy among the pediatric population. In Brazil, Vieira et al. [2] carried out an epidemiological survey with 30 pediatric gastroenterologists in 20 cities of 11 states, in 5 regions, where a prevalence of suspected allergy to cow's milk was observed in $5.4 \%$ ( $n=513$ ) of the 9,478 children consulted, and an incidence of $2.2 \%$ 
$(n=211)$ in a study period of forty days [2]. Several guidelines for the diagnosis and treatment of CMA have been published in recent years $[1,3,4]$. These guidelines recommend the exclusion of cow's milk and derivatives from the mother's diet to reduce the allergenic potential of breast milk or, if it is not possible to breastfeed, the use of extensively hydrolyzed milk-based formula (eHF) as the first option for diagnosis and treatment, which is well tolerated by about $90 \%$ of infants [3]. Infant formulas based on plant proteins (such as extensively hydrolyzed protein from rice and soy) and free amino acid based formulas (AAFs) can also be considered, provided that aspects such as the child's age, safety, efficacy, nutritional composition (quality of amino acid composition, presence of lactose and prebiotics etc.), impairment of nutritional status and clinical manifestations, including the severity, have been considered [3-5]. Formulas intended for the treatment of CMA are characterized by a considerably reduced palatability, due to the hydrolysis process of their proteins [6]. Factors affecting palatability that have been identified include the degree of hydrolysis, protein source and temperature of the infant formulas during consumption [7-9].

The palatability of infant formulas has a proportional influence on their acceptability, i.e., the more palatable, the greater the infant's chances of consuming sufficient quantities for their adequate growth and improvement of symptoms [10]. This relationship occurs both in infants, who have an innate preference for sweet taste and aversion to sour and bitter tastes, as well as on the part of family members responsible for their feeding, who may also influence the type of formula to be consumed, according to their own sensorial perceptions [11]. In addition to the influence on acceptability, the sensory experiences that infants have in the first months of life may have a relationship with food preferences both in childhood and in adulthood [12]. This way, an unpleasant palatability could adversely affect palate development, with health professionals observing a selective feeding behavior in children with CMA [10-12]

Currently, in the scientific literature, there are few studies of sensory analysis performed with infants, due to the obvious limitations of measuring their degree of preference and acceptability, and even from the directly responsible for their feeding. However, it is extremely important to determine the sensory perceptions that the mothers of children with CMA have regarding the different formulas to be used in the nutrition of their children, since in many cases these formulas may be the only source of feeding for the infant, which may be at growth and development risk, if the appropriate volume is not consumed. Vieira et al. [2] demonstrated that approximately $24 \%$ of infants with CMA present impaired nutritional status in relation to the height / age index [2]. The objective of this study was to evaluate the sensory perceptions of Brazilian mothers regarding the formulas for the treatment of CMA, through the application of acceptability and preference tests, considering the appearance and odor of the product in the can, and the odor, flavor and residual taste of the reconstituted product.

\section{Methods}

This double-blind study was carried out with Brazilian mothers of children that were or had been treated for CMA, to assess the sensory perception and relative palatability of different hydrolyzed $\mathrm{f}$ and amino acid-based formulas. Five different formulas were presented in random order, both as a powder and after reconstitution. The powdered products were presented in a can without identification of type, brand and manufacturer. All tested formulas were rigorously reconstituted according to the manufacturers' instructions, which were presented on the product labels and were served as indicated. Ninety healthy volunteers, mean age $31.4 \pm 6.5$ years of age (range 18-42 years), not trained for palatability and sensory perception tests, were selected by a research and market analysis agency, via online recruitment, in a digital social network group of mothers of children with CMA of a, respecting the following criteria:

Inclusion Criteria: be a mother of a child diagnosed with cow's milk allergy that receives or had already received an infant formula for CMA treatment, either through a special formula dispensing program or direct purchase at the point of sale, according to medical prescription.

Exclusion Criteria: smoking, airway problems, current or previous week before the recruitment cold or flu, diagnosis of diseases such as cancer, diabetes or chronic diseases of the respiratory tract. All the information was mentioned by the participants themselves, and there was a double check of the data, both for the online recruitment and the day of convocation for the analysis test. The participants only performed the sensory analysis after accepting and signing an informed consent form. The analyzed formulas were received in powder form, with a valid expiration date, in packages not damaged and properly sealed, of the following types and brands: Formula WH: formula with highly hydrolyzed whey protein without lactose (Pregomin Pepti-Danone Early Life Nutrition), Formula WHL: formula with extensively hydrolyzed whey protein with lactose (Aptamil Pepti-Danone Early Life Nutrition), Formula CH: Formula with extensively hydrolyzed casein protein (Progestimil -Mead Johnson), Formula RH: formula with extensively hydrolyzed rice protein (Novamil Rice -Biolab) and Formula AA: free amino acid formula (Neocate LCP-Danone Advanced Medical Nutrition). The formulas were presented to the mothers coded by 3-digit numbers, in a sequential monadic sequence according to a complete randomized block design. For the cleaning of the palate at the beginning of the test and between the samples, still mineral water was available. The formulas were evaluated for the acceptability of the product appearance and odor in the can, and after preparation, for the acceptability of odor, taste, taste that remains in the mouth (residual) and in general, through a hedonic scale of nine points $(9=$ like extremely, $5=$ neither like nor dislike and 1 = dislike extremely) [13]. The preference test was performed with the samples as powder and reconstituted, in which the mothers placed the samples in order of preference according to 
their opinion (where the first position refers to the sample that they liked best and the last one to the sample that they most disliked).

The test was conducted in individual booths with fluorescent lamps illumination and equipped with Compusense ${ }^{\circledR}$ Five 5.6 software (Compusense Inc., Guelph, ON, Canada) for data collection and analysis. The data on the attributes evaluated by means of hedonic scale were submitted to analysis of variance and Tukey Test for comparison of means. In the preference evaluation, the results for the sum of the sorting positions were treated based on the Friedman Test and Fisher Test for comparison between the samples at the 5\% significance level. The research was carried out in partnership with the Danone Early Life Nutrition Science Department and the Institute of Food Technology (ITAL, Campinas, São Paulo) and was approved by the ethics committee of the Hospital and Maternity São Luís (CAAE: 80351217.0.0000.0087).

\section{Result}

The characterization of the group of mothers recruited for the study is shown in Table 1 . At the time of the test, $42 \%$ of participants reported the previous use of a whey hydrolysate and 37\% the previous use of the formula based on amino acids. The majority of previous users had obtained these products at high cost from a pharmacy (62\%).When analyzing the information about education and family income of the participants, no correlation was observed with any acceptability variable ( $p>0.05$ for all cases).However, when correlating education with prior or previous contact with the CMA treatment formulas, correlations were observed for WHL and WH, i.e. WHL was consumed more frequently by the less educated groups $(\mathrm{p}=0.02)$, whereas WH was consumed more frequently by the higher education levels $(p=0.04)$. Mothers who did not have prior contact with the $\mathrm{WH}$ formula, gave a higher score to the general evaluation of this product $(p=0.05)$ and lower to residual taste ( $p=0.04)$ Table 2 shows the mean results of the acceptability of the appearance and odor in the can and, after preparation, of the acceptability of smell, flavor, aftertaste and overall acceptability, as well as the results of evaluation on preference. WHL and WH were significantly preferred in relation to the other formulas with the significance level of 5\%, in all the variables evaluated.

Table 1: Maternal age, education and family income.

\begin{tabular}{|c|c|c|}
\hline \multicolumn{2}{|c|}{ Variables } & \multirow{2}{*}{$\begin{array}{c}\% \text { (n) } \\
6 \%(n=05) \\
\end{array}$} \\
\hline \multirow{6}{*}{ Age group } & 18 to 20 & \\
\hline & 21 to 25 & $19 \%(n=17)$ \\
\hline & 26 to 30 & $14 \%(n=13)$ \\
\hline & 31 to 35 & $31 \%(n=28)$ \\
\hline & 36 to 40 & $26 \%(n=23)$ \\
\hline & 41 to 42 & $4 \%(n=04)$ \\
\hline \multirow{3}{*}{ Maternal education $(n=90)$} & Incomplete high school & $12,2 \%(n=11)$ \\
\hline & Complete high school & $70 \%(n=63)$ \\
\hline & Higher education & $17,8 \%(n=16)$ \\
\hline \multirow{4}{*}{ Family income $(\mathrm{n}=90)$} & 1 to 2 Minimum wage & $61,1 \%(n=55)$ \\
\hline & More than $2 \mathrm{MW}$ & $26,7 \%(\mathrm{n}=24)$ \\
\hline & Unemployed & $3,3 \%(n=03)$ \\
\hline & Refused to respond & $8,9 \%(n=08)$ \\
\hline
\end{tabular}

Table 2: Results obtained in the evaluation of the acceptability and preference of the evaluated samples.

\begin{tabular}{|c|c|c|c|c|c|c|}
\hline Acceptability $^{\mathbf{1}}$ & WHL & WH & AA & RH & CH & p \\
\hline Appearance (can) & $7.3(1.2) \mathrm{a}$ & $7.3(1.0) \mathrm{a}$ & $6.0(2.1) \mathrm{b}$ & $5.6(2.1) \mathrm{b}$ & $6.0(1.8) \mathrm{b}$ & $<0.01$ \\
\hline Smell (can) & $6.4(1.8) \mathrm{a}$ & $6.6(1.5) \mathrm{a}$ & $5.0(2.4) \mathrm{b}$ & $5.1(2.0) \mathrm{b}$ & $5.1(1.9) \mathrm{b}$ & $<0.01$ \\
\hline Smell & $5.9(1.9) \mathrm{a}$ & $5.9(2.0) \mathrm{a}$ & $4.3(2.1) \mathrm{bc}$ & $4.9(2.2) \mathrm{b}$ & $4.2(2.1) \mathrm{c}$ & $<0.01$ \\
\hline Flavor & $5.6(2.1) \mathrm{a}$ & $5.5(2.1) \mathrm{a}$ & $3.4(2.0) \mathrm{bc}$ & $4.0(2.1) \mathrm{b}$ & $3.1(1.9) \mathrm{c}$ & $<0.01$ \\
\hline Aftertaste & $5.5(2.1) \mathrm{a}$ & $5.4(2.1) \mathrm{a}$ & $3.2(1.8) \mathrm{c}$ & $4.0(2.1) \mathrm{b}$ & $3.2(1.9) \mathrm{c}$ & $<0.01$ \\
\hline Overall & $5.7(2.2) \mathrm{a}$ & $5.5(2.1) \mathrm{a}$ & $3.3(2.0) \mathrm{c}$ & $4.1(2.2) \mathrm{b}$ & $3.1(1.9) \mathrm{c}$ & $<0.01$ \\
\hline Preference $^{2}$ & $189 \mathrm{~b}$ & $206 \mathrm{~b}$ & $328 \mathrm{a}$ & $300 \mathrm{a}$ & $327 \mathrm{a}$ & 0 \\
\hline
\end{tabular}

Note:

1. Results expressed as mean (standard deviation) of 90 evaluations. Means followed by different letters differ significantly from each other at $\mathrm{p}<0.05$ by Tukey's test.

2. Sums of preference positions followed by different letters differ significantly from each other at $\mathrm{p}<0.05$ by the Friedman and Fisher test. Samples with lower ordering sums are preferred over those with higher sums. 
For the appearance evaluation, WHL and WH, with means close to "like moderately" in the employed scale, did not differ among themselves and were better accepted than AA, RH and $\mathrm{CH}$, which obtained means of "like slightly" and did not differ significantly among themselves.For the smell in the can, WHL and WH, which means situated between "like moderately" and "like slightly", did not differ among themselves, but differed from the other samples that presented means corresponding to "neither like nor dislike". After preparation, WHL and WH presented mean values of "like slightly" for the smell and did not differ among themselves, but showed differences from the other samples, where RH presented mean corresponding to "neither like or dislike" and differed significantly from $\mathrm{CH}$. AA, with intermediate mean, did not differ from $\mathrm{HR}$ or $\mathrm{CH}$. Regarding flavor, WHL and WH, with means between "like slightly" and "neither like or dislike", did not differ between themselves, but differed significantly from the other samples. Regarding the aftertaste and the overall acceptability, WHL and WH showed means between "like slightly" and "neither like or dislike", did not differ significantly among them, but differed from other samples at $\mathrm{p}<0.05$. RH with mean corresponding to "slightly dislike", differed from $\mathrm{AA}$ and $\mathrm{CH}$, which presented mean corresponding to "moderately dislike". Overall, the mean acceptance of sensory characteristics of the eHFs basedon hydrolyzed whey protein was higher than the other formula categories.

Figure 1 shows the percentages of: acceptance (corresponding to values 6 to 9), indifference (value 5) and rejection (values 4 to 1 ), for the samples, regarding odor, taste, residual taste and in general. WHL and WH presented the highest percentages of acceptance: in general, between $60 \%$ and $70 \%$ for all evaluated attributes. The other samples presented high rejection frequencies: in general, close to, or above $70 \%$ for $\mathrm{AA}$ and $\mathrm{CH}$ and, in general, between $50 \%$ and $60 \%$ for HR. Figure 1 Percentages of acceptance (corresponding to values 6 to 9), indifference (value 5) and rejection (values 4 to 1) of the samples for smell (a), flavor (b), aftertaste (c) and overall acceptability (d), according to the evaluation of the mothers who participated in the test.

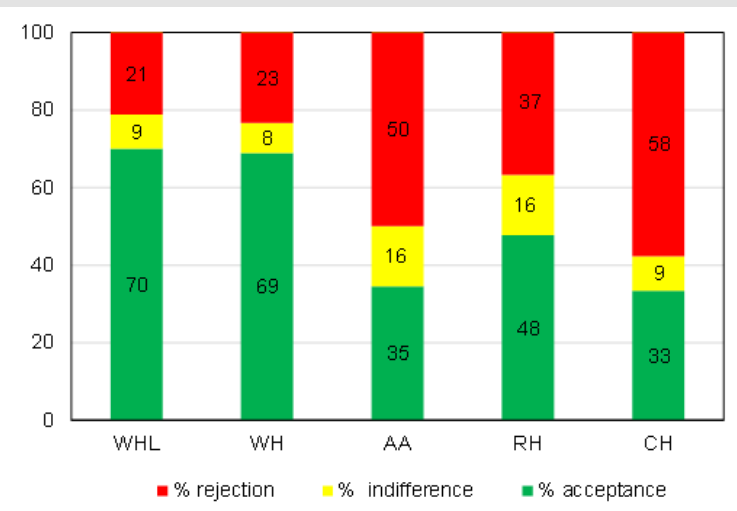

(a)

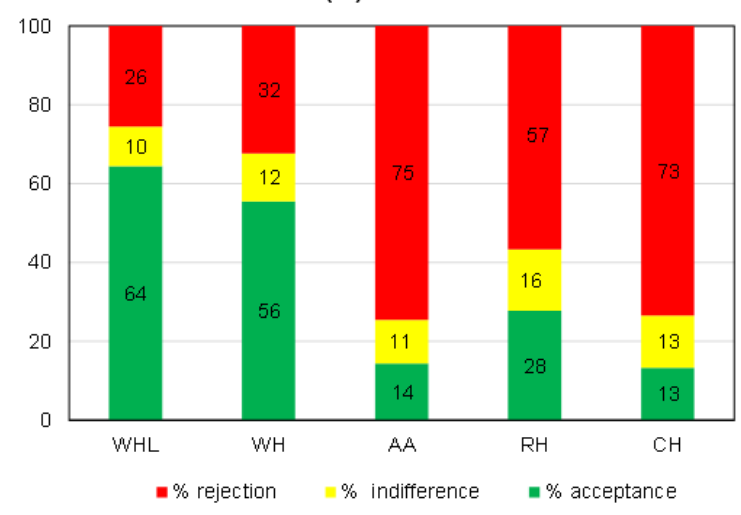

(c)

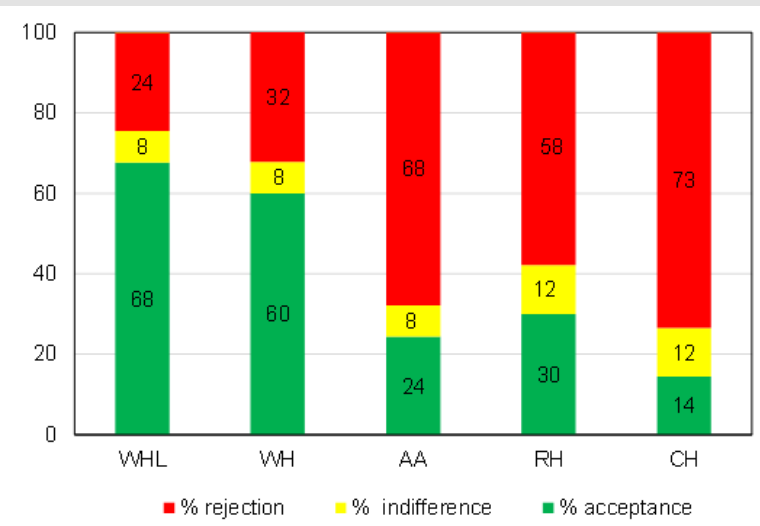

(b)

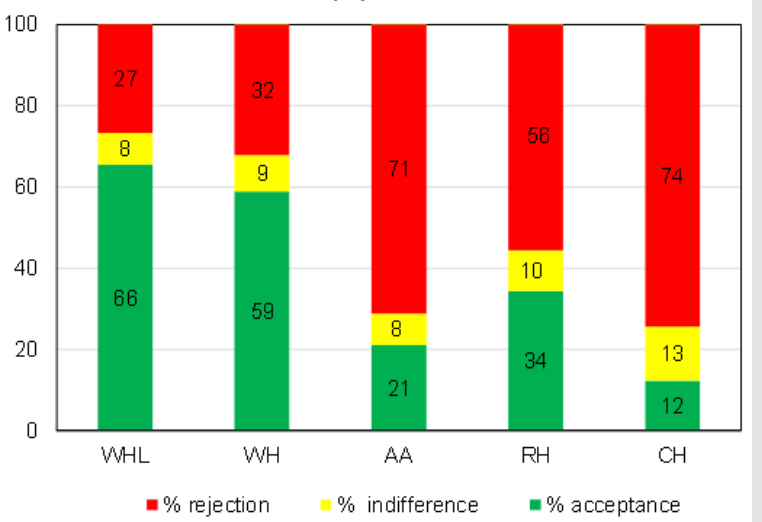

(d)

Figure 1: Percentages of acceptance (corresponding to values 6 to 9), indifference (value 5) and rejection (values 4 to 1) of the samples for smell
a) Flavor,
b) Aftertaste,
c) Overall acceptability,
d) According to the evaluation of the mothers who participated in the test. 


\section{Discussion}

This is the first Brazilian study that evaluated the palatability of the substitution formulas available to children allergic to cow's milk proteins in mothers with children with CMA. The results show that whey eHF were chosen as better palatability compared to eHF from rice, casein and AAF.It is considered appropriate to evaluate palatability as the sum of taste, residual taste and odor because they all contribute decisively to the taste sensation, which may favor a greater intake of formula per day. The sensory world of infants is ever changing and dynamic and most evident as they begin the transition from an all-milk diet to one containing solid foods. Early flavor experiences in amniotic fluid, milk, and solid foods affect infants' taste acceptance patterns and infants communicate their acceptance by both intake and facial displays [11]. Although there are differences in taste preference between infants and adults, several studies have reported that infants are able to discriminate different taste characteristics from birth and respond to stimuli, especially sweet and bitter with a pattern of responses similar to those observed in adults $[9,14,15]$.

Mennella et al. [10] suggests that plasticity in the palate is related to age. The adaptive reasoning of this fact reflects the importance of infants becoming familiar with the flavors that their mothers have in their usual diet and that is transmitted through breast milk [16]. These flavors are the ones likely to be exposed or have contact during weaning and reflect the culinary traditions of their families.The international recommendations on the approach in the choice of formulas are based on the allergenic potential but also on the following factors: composition, costs, availability and acceptance by the infant [3]. Several studies and consensus have shown that the palatability of serum-based eHF is considered to be very good, superior to the other types of formulas [3,17]. A double-blind study was performed with 50 evaluators, and 12 different formulas were tested. This study correlated the degree of hydrolysis of the formulas with their palatability, showing that there is a negative correlation between the degree of hydrolysis and the taste: the higher the degree of hydrolysis, the worse the flavor [7]. The relevance of palatability, especially the hydrolyzate of the whey protein, as observed in this study, in the treatment of CMA is enormous, since ensuring the acceptance of the hydrolyzed formula by the patient, not only will there be remission of symptoms, but it will also contribute to the acquisition of the oral tolerance and nutrient intake, and consequently for patient growth and development. The best taste and acceptance are also of greater relevance when it comes to patients who have undergone several formula changes or when they are older than 6 months because, due to contact with different flavors, these patients become more selective.

The eHFs and AAF are notorious for their unpleasant bitter and sour taste and nauseating smell and aftertaste, due to the presence of peptides and amino acids. These experiences have an effect on children's food acceptance and the variety of foods consumed can have an impact on infant health.However, it is important to also consider formulas acceptance that interfere with compliance in clinical practice. Many factors contribute to the taste development of the child, and the influence of an eHF or an AAF is not necessarily negative for taste development in these children [9]. The infant's acceptance of the formula offered is as important as the allergenic potential of the formulas. When a patient is given a formula to alleviate the symptoms of CMA, he may often have experienced discomfort or pain that also contribute to anorexia and refusal to feed. Another important factor is the presence of inflammation, which increases the demand for nutrients, making good diet acceptance even more important.However, it is important to also consider formulas acceptance that interfere with compliance in clinical practice. Many factors contribute to the taste development of the child, and the influence of an eHF or an AAF is not necessarily negative for taste development in these children [9].

This study aims to reinforce that the treatment of CMA requires adherence of the patient and his / her relatives, being this a fundamental point so that the result of the treatment is the best possible, i.e.: without sequels and residual nutritional deficits, greater security, lower level of stress. All this enabling a better quality of life for the child involved, a condition that is permeated by the acceptability and palatability of the formulas used as substitutes. In conclusion, this study highlights that, in addition to the greater tolerability ( $\sim 90 \%$ of cases) already known in the literature regarding eHF, the relevance of the appropriate nutritional intake, the differential in the flavor of eHF based on whey in Comparison with $\mathrm{eHF}$ of rice, casein and AAF, as well as the importance of the mothers' perception and awareness of the sensorial characteristics of the formulas prescribed for the management of CMA, can be an important factor for the adherence and success of the treatment. Most of the studies that deal with the theme of CMA have as main theme the diagnosis, treatment, trigger test, remission of symptoms and the role of the diet of exclusion. However, it is also necessary that the parent's perception be explored, especially regarding the sensory/ organoleptic characteristics of the possible infant formulas used for CMA, since the parents' anxiety about the palatability of the formula or rejection of the infant can impact on the improvement / recovery of the condition, with possible unnecessary cost increase (Annex 1).

\section{Acknowledgement}

None

\section{Conflicts of Interest}

The authors have no conflicts of interest.

\section{References}

1. Boyce JA, Assaad A, Burks W, Jones SM, Sampson H, et al. (2010) Guidelines for the diagnosis and management of food allergy in the United States: report of the NIAID-sponsored expert panel. J Allergy Clin Immunol 126(6 Suppl): S1-58. 
2. Vieira MC, Morais MB, Spolidoro JVN, Toporovski MS, Cardoso AL, et al (2010) A survey on clinical presentation and nutritional status of infants with suspected cow' milk allergy. BMC Pediatr 10.

3. Koletzko S, Niggemann B, Arato, Dias J, Heuschkel R, et al. (2012) Diagnostic approach and management of cow's-milk protein allergy in infants and children: ESPGHAN GI Committee practical guidelines. Pediatr Gastroenterol Nutr 55(2): 221-229.

4. Venter C, Brown T, Shah N, Walsh J, Fox AT (2013) Diagnosis and management of non-IgE-mediated cow's milk allergy in infancy - a UK primary care practical guide. Clin Transl Allergy 3(1): 1-11.

5. De Greef E, Hauser B, Devreker T, Veereman-Wauters G, Vandenplas Y (2012) Diagnosis and management of cow's milk protein allergy in infants. World Journal of Pediatrics 8(1):19-24.

6. Mennella JA, Beauchamp GK (2005) Understanding the origin of flavor preferences. Chemical Senses.

7. Pedrosa Delgado M, Pascual CY, Larco JI, Martín Esteban M (2006) Palatability of hydrolysates and other substitution formulas for cow's milk-allergic children: A comparative study of taste, smell, and texture evaluated by healthy volunteers. J Investig Allergol Clin Immunol 16(6): 351-356.

8. De Jong NW, Sprikkelman AB, Oude Elberink HNG, Arends NJT, VliegBoerstra BJ (2014) Blinded sensory evaluation of extensively hydrolyzed formulas and amino acid formulas. Annals of Allergy, Asthma and Immunology 235-236.

\section{ISSN: 2574-1241}

DOI: $10.26717 /$ BJSTR.2020.25.00416

Matias Epifanio. Biomed J Sci \& Tech Res

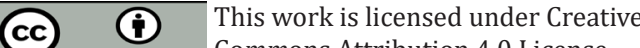
Commons Attribution 4.0 License

Submission Link: https://biomedres.us/submit-manuscript.php
9. Miraglia Del Giudice M, DAuria E, Peroni D, Palazzo S, Radaelli G, et al. (2015) Flavor, relative palatability and components of cow's milk hydrolysed formulas and amino acid-based formula. Ital J Pediatr 41(1): 42.

10. Mennella JA, Jagnow C, Beauchamp GK (2001) Prenatal and postnatal flavor learning by human infants. Pediatrics 107(6): E88.

11. Beauchamp GK, Mennella JA (2011) Flavor perception in human infants: Development and functional significance. Digestion 1-6.

12. Mennella JA, Beauchamp GK. Flavor experiences during formula feeding are related to preferences during childhood. Early Hum Dev 68(2): 7182.

13. Meilgaard MC, Carr BT, Civille GV (2007) Sensory Evaluation Techniques, Fourth Edition. Sensory Evaluation Techniques, (4 ${ }^{\text {th }}$ Edn.)., pp. 464.

14. Steiner JE (1979) Human facial expressions in response to taste and smell stimulation. Adv Child Dev Behav 13(C): 257-295.

15. Ulla H, Antti K, Oskar L, Mari S (2016) Genetic basis of flavor sensitivity and food preferences. Flavor: From Food to Behaviors, Wellbeing and Health pp. 203-227.

16. Mennella JA, Lukasewycz LD, Castor SM, Beauchamp GK (2011) The timing and duration of a sensitive period in human flavor learning: a randomized trial. Am J Clin Nutr 93(5): 1019-1024.

17. Fiocchi A, Dahda L, Dupont C, Campoy C, Fierro V, et al. (2016) Cow's milk allergy: towards an update of DRACMA guidelines. World Allergy Organ J 9(1).

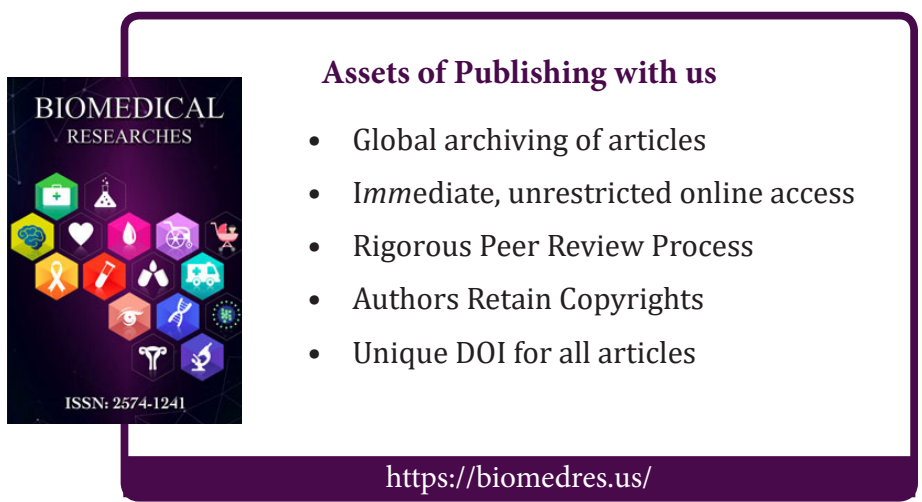

